\title{
A NEW METHOD OF DETERMINING THE SENSITIVITY OF $M$. TUBERCULOSIS TO CHEMOTHERAPEUTIC AGENTS
}

\author{
BY
}

\author{
A. M. BEEMER AND C. H. L. HOWELLS \\ From the King George V Hospital, Durban, S. Africa
}

(RECEIVED FOR PUBLICATION DECEMBER 1, 1954)

Many methods are available for determining the sensitivity of $M$. tuberculosis to various chemotherapeutic agents. These may be divided broadly into three groups. In the first group the streptomycin is incorporated into solid media, such as that of Herrold (1931) or of Löwenstein (1930) and Jensen (1932) (Pyle, 1947 ; Johnson, 1950 ; Youmans, Ibrahim, Sweany, and Sweany, 1950 ; Tinne and Henderson, 1950; Wildy, 1951). The techniques included in the second group necessitate the use of liquid semi-synthetic media such as that of Proskauer and Beck (1894) as modified by Youmans (1944), or the medium of Long (1919) as modified by Dubos (1945) and Dubos and Davis (1946) (Medical Research Council report, 1948; Vollum, 1952). The methods of the third group of workers have not gained much popularity, as they present numerous technical difficulties. Emmart (1945) used chick embryos, while Cummings and Drummond (1949) recommended a slide culture technique. Only those in the first group can be considered practicable for use in the laboratory where there is a shortage of technical staff. The method to be described (modified from Beemer, 1951) is designed to fulfil this need.

\section{Method}

Preparation of Medium. - Löwenstein-Jensen medium is prepared as recommended by Jensen (1932) and poured into $3 \frac{1}{2}$-in. petri dishes, $35 \mathrm{ml}$. of medium being required for each dish.

The petri dishes are then inspissated at $80^{\circ} \mathrm{C}$. for one hour on the first day and for a similar period at $75^{\circ} \mathrm{C}$. on the second day. The water of condensation which collects on the lids of the petri dishes must be removed carefully by tilting the lids while the dishes are in the inspissator.

Finally the dishes are incubated at $37^{\circ} \mathrm{C}$. overnight. This dries the medium suitably and any con- taminated dish can be discarded. (With attention to the few precautions and details mentioned, such con $-N$ tamination is very rare.)

From the same batch of medium ordinary Löwen- $\rightarrow$ stein-Jensen slopes are prepared in screw-capo McCartney bottles to be used as the controlse referred to later.

Preparation of Streptomycin-Liquid Paraffin Mix ture.-One gram of streptomycin is dissolved in $2 \mathrm{ml}$ : of sterile $\mathrm{M} / 15$ phosphate buffer of $p \mathrm{H} 7.8$ and addedo to $78 \mathrm{ml}$. of liquid paraffin, giving a concentration of 1 in 80 streptomycin.

Procedure.-Every petri dish is inoculated with four strains of $M$. tuberculosis, of which one is $\mathrm{H} 37 \mathrm{Rv} \stackrel{2}{\Rightarrow}$ A sterile throat swab is rubbed over Löwenstein-윽 Jensen culture of the strain to be tested, and is then streaked across the medium in the petri dish. The

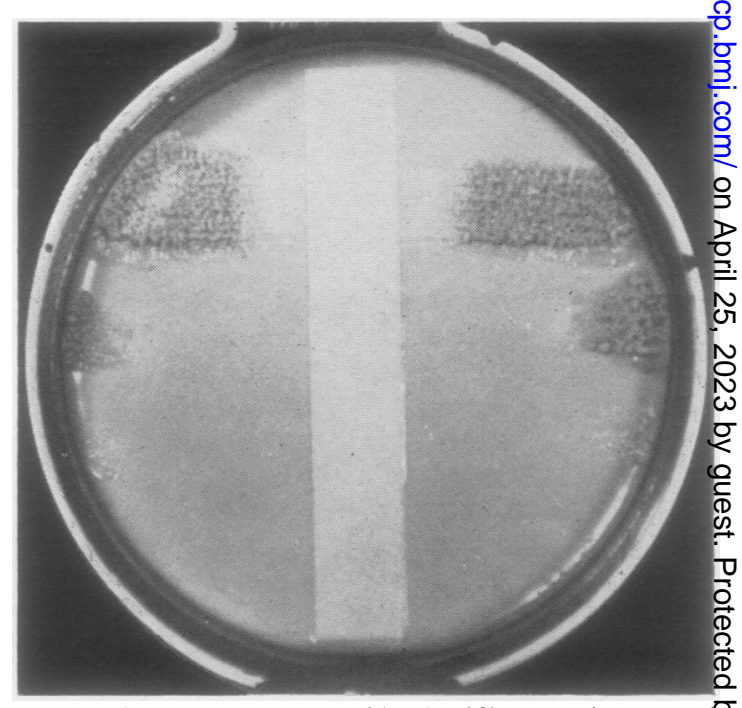

FIG. 1.-Löwenstein-Jensen plate with strip of filter paper impregnated with streptomycin. The three cultures show varying degrees of inhibition. 
same swab is immediately inoculated on a fresh Löwenstein-Jensen slope as a control to make sure the test culture is still viable, and to compare the luxuriance of growth with that on the sensitivity plate.

A strip of sterile filter paper $3 \frac{1}{4}$ in. $\times \frac{1}{2}$ in. is laid on the inoculated medium in the petri dish at right angles to the streaks of the organisms under test. The streptomycin-liquid paraffin emulsion $(0.2 \mathrm{ml}$.) is evenly dispersed over the strip using a sterile Luer lock syringe fitted with a 17-g. Gurr-Sico hypodermic needle. An identical strip of sterile filter paper is then laid on the first to absorb the excess streptomycin-liquid paraffin emulsion, and the plate incubated at $37^{\circ} \mathrm{C}$. for 10 days. To prevent drying, the plates are placed in a tightly lidded container with a small piece of damp gauze at the bottom.

Interpretation of Results.-After incubation confluent growth along the line of inoculation appears at a variable distance from the strip of filter paper (Fig. 1). The zones of inhibition are compared with that produced by the standard strain H37Rv. The distance between the edge of the filter paper and the rim of the petri dish at its diameter is arbitrarily divided into four equal parts. Each of these parts is designated with a plus symbol. Thus, if any strain is inhibited for one of these divisions, it is graded with 1 plus inhibition, and if for two divisions 2 plus, and so on. This inhibitory zone is then compared with that produced by the standard strain $H 37 R v$, which usually shows a 2 to 3 plus inhibition. For example, if the test organism shows 1 plus inhibition, i.e., growth is inhibited for a distance equal to onequarter the radius, and the control H37Rv shows 2 plus inhibition, the resistance of the test organism is reported as $2 \times \mathrm{H}$. The length of the zone of inhibition depends on the amount of streptomycin which has diffused into the medium, and this may be affected by the physical properties of the medium and other factors. The quantitative expression of the results is therefore arbitrary, but is in reasonably close agreement with more strictly quantitative methods.

In some cases a few scattered colonies appear near the strip where confluent growth is inhibited by the streptomycin. In these instances the sensitivity of the strain of $M$. tuberculosis is determined as described above, but in addition the presence of the few resistant colonies is recorded (always provided that the control slope showed a confluent growth). It seems probable that this indicates the presence of resistant variants in a predominantly sensitive culture.

The table shows the results of sensitivity tests on 82 cultures by the method described and by the fluid culture method (Vollum, 1952). The results are identical in 26 cases and closely approximate in 36 cases. In no case are the results grossly divergent. For clinical purposes, the results of either test would be acceptable. Three strains which were insensitive by the plate method showed greatly increased resistance by the fluid culture method. The higher resistance found in one cul- ture by the fluid method is shown by the plate method to be due to a few resistant colonies.

TABLE

COMPARATIVE RESULTS RECORDED IN TERMS OF RESISTANCE

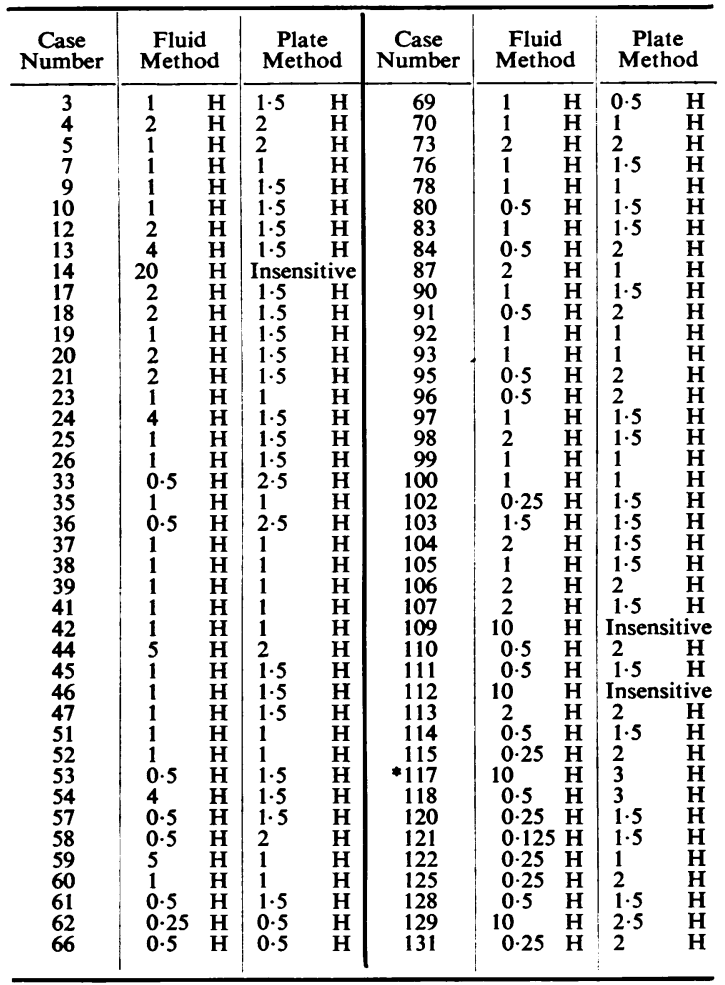

* Scanty colonies were present near strip.

\section{Discussion}

The simple plate technique described here has been shown to give results which are consistent and reproducible with the control culture H37Rv and which are in good agreement with those obtained by the serial dilution technique of Vollum (1952).

In our experience the method has a number of advantages which have prompted us to report our findings. Thus results are obtained relatively quickly and many cultures can be examined with the minimum of glassware and technical skill. Moreover, sensitivity can be assessed on a qualitative basis, and it is possible to see whether sensitive and insensitive organisms are present in the same culture.

Our thanks are due to Dr. R. L. Vollum for his advice and criticism; Dr. B. A. Dormer for making 
available the necessary facilities for carrying out this investigation; Mr. O. F. Gibbs and Miss J. C. M. Holzhaus for invaluable technical assistance; and Mr. K. S. Mostert for the photographs.

Dr. Beemer is working under the auspices of the South African Council for Scientific and Industrial Research. Dr. Howells is working for the Tuberculosis Research Association.

\section{REFERENCES}

Beemer, A. M. (1951). S. Afr. med. J., 25, 357.

Cummings, M., and Drummond, M. (1949). Amer. Rev. Tuberc., $59,599$.

Drummond, M. C., Lewis, G. T., and Cummings, M. M. (1951). Dis. Chest, 19, 158.

Dubos, R. J. (1945). Proc. Soc. exp. Biol., N.Y., 58, 361.

and Davis, B. D. (1946). J. exp. Med., 83, 409.
Emmart, E. W. (1945). Publ. Hlth Rep. (Hash.), 60, 1415.

Herrold, R. D. (1931). J. Infect. Dis., 48, 236.

Holt, H. D., and Cruickshank, R. (1949). Monthly Bull. Minist. Hlth, Lond., 8, 103.

Jensen, K. A. (1932). Zbl. Bakt. I. Abt. Orig., 125, 222

Johnson, B. H. (1950). Amer. Rev. Tuberc., 61, 578.

Long, E. R. (1919). Ibid., 3, 86.

Löwenstein, E. (1930). Dtsch. med. Wschr., 56, 1010.

Medical Research Council (1948). Lancet, 2, 862.

Proskauer, B., and Beck, M. (1894). Z. Hyg. InfektKr., 18, 128.

Pyle, M. M. (1947). Proc. Mayo Clinic, 22, 465.

Tinne, J. E., and Henderson, J. L. (1950). Lancet, 2, 901.

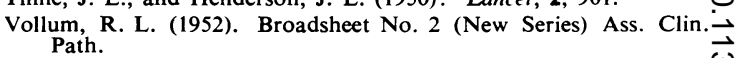

Wildy, P. (1951). Journal of Clinical Pathology, 4, 421.

Youmans, G. P. (1944). Proc. Soc. exp. Biol., N.Y., 57119. Ibrahim, A., Sweany, J., and Sweany, H. C. (1950). Amer. 으 Rev. Tuberc., 61, 569. 